\title{
RELAÇÕES DE GÊNERO NO MOVIMENTO DOS TRABALHADORES SEM TERRA - MST: PERSPECTIVAS A PARTIR DA CONCEPÇÃO PEDAGÓGICA DO MOVIMENTO
}

\author{
RELACIONES DE GÉNERO EN EL MOVIMIENTO DE LOS TRABAJADORES SIN \\ TIERRA - MST: PERSPECTIVAS A PARTIR DE LA CONCEPCIÓN PEDAGÓGICA \\ DEL MOVIMIENTO
}

GENDER RELATIONS IN THE LANDLESS WORKERS MOVEMENT - MST:
PERSPECTIVES FROM THE DESIGN OF EDUCATIONAL MOVEMENT

Claudia Pereira de Pádua SABIA ${ }^{1}$

Tânia Suely Antonelli Marcelino BRABO²

RESUMO: O estudo tem por objetivo identificar às relações de gênero no interior do Movimento dos Trabalhadores Sem Terra e se o processo educativo do MST tem contribuído para as ações e discussões sobre o tema. Este trabalho faz parte de um projeto intitulado "Concepções teórico-práticas de educação e trabalho no MST" e contou com o financiamento do CNPQ. Neste estudo, a metodologia utiliza à abordagem qualitativa e as pesquisas bibliográfica, documental e a coleta de dados. A coleta de dados consistiu em entrevistas com coordenadoras de escolas localizadas em assentamentos do MST e uma ex-dirigente do Setor Nacional de Gênero do Movimento. Como resultados, identificamos no desenvolvimento das questões de gênero no MST, alguns avanços alcançados, como por exemplo, a titularidade conjunta, dando legalmente as mulheres os mesmos direitos de posse e uso da terra e, também a participação das mulheres em $50 \%$ de todas as instâncias políticas do Movimento que demandou grande esforço e acentuado processo de formação das mesmas. Entretanto, permanece o grande desafio de criar possibilidades de uma maior igualdade na divisão do trabalho realizado e de oportunidades para as mulheres Sem Terra.

PALAVRAS-CHAVE: Gênero. Educação no MST. Movimentos sociais.

RESUMEN: El estudio tiene por objetivo identificar a las relaciones de género en el interior del Movimiento de los Trabajadores Sin Tierra y si el proceso educativo del MST ha contribuido a las acciones y discusiones sobre el tema. Este trabajo forma parte de un proyecto titulado "Conceptos teórico-prácticos de educación y trabajo en el MST" y contó con el financiamiento del CNPQ. En este estudio, la metodología utiliza el abordaje cualitativo y las investigaciones bibliográfica, documental y la recolección de datos. La recolección de datos consistió en entrevistas con coordinadoras de escuelas ubicadas en asentamientos del MST y

${ }^{1}$ Universidade Estadual Paulista (UNESP), Marília - SP - Brasil. Docente do Departamento de Administração e Supervisão Escolar do Departamento de Administração e Supervisão Escolar da FFC. Doutora em Educação. ORCID: <https://orcid.org/0000-0001-8173-6420> E-mail: claudia.sabia@unesp.br

${ }^{2}$ Universidade Estadual Paulista (UNESP), Marília - SP - Brasil. Docente do Departamento de Administração e Supervisão Escolar da FFC e do Programa de Pós-Graduação em Educação Líder do Grupo de Pesquisa NUDISE - Núcleo de Gênero e Diversidade Sexual na Educação. Vice Coordenadora do Núcleo de Direitos Humanos e Cidadania de Marília. Pós-doutoramento em Educação. ORCID: <https://orcid.org/0000-0002-9833-0635> Email: tamb@terra.com.br 
una ex dirigente del Sector Nacional de Género del Movimiento. Como resultados, identificamos en el desarrollo de las cuestiones de género en el MST, algunos avances logrados, como por ejemplo la titularidad conjunta, dando legalmente a las mujeres los mismos derechos de tenencia y uso de la tierra y, también, la participación de las mujeres en el 50\% de todas las instancias políticas del Movimiento que demandó gran esfuerzo y acentuado proceso de formación de las mismas. Sin embargo, sigue siendo el gran desafío de crear posibilidades de una mayor igualdad en la división del trabajo realizado y de oportunidades para las mujeres sin Tierra.

PALABRAS CLAVE: Género. Educación en el MST. Movimientos sociales.

ABSTRACT: The study aims to identify of the gender relations within the Landless Workers Movement (MST) and if the MST educational process has contributed to the actions and discussions on the topic. This work is part of a project entitled "Theoretical and practical conceptions education and work in the MST" and had the financing CNPQ. In this study, the methodology uses the qualitative approach and the bibliographical research, document and data collection. Data collection consisted of interviews with coordinators of schools in MST settlements and a former leader of the National Movement Gender Sector. As a result, we have identified the development of gender issues in the MST, some progress was made, for example, joint ownership, giving legally women the same rights of ownership and use of land and also the participation of women in 50\% of all the Movement's political bodies which required great effort and enhanced process of forming the same. However, remains the great challenge of creating possibilities for greater equality in the division of work and opportunities for women landless.

KEYWORDS: Gender. Education in MST. Social movements.

\section{Introdução}

A presença de mulheres no Movimento de Trabalhadores Rurais Sem Terra/MST é encontrada na criação do movimento, desde o início da década de 1980. Num primeiro momento, elas apresentam identidades subordinadas à ordem patriarcal, à modelos instituídos no tempo histórico e pela cultura, alimentados pela ordem binária e universalizada, e sem o reconhecimento de suas práticas nas instâncias sociais, econômicas, políticas e organizativas do MST. Além disso, conforme a literatura mostra, nesta perspectiva patriarcal, como em outros espaços da sociedade e da ciência, elas são invisibilizadas pelo domínio hierárquico da categoria de classe social, que orienta o Movimento e homogeneíza os sujeitos em coletivos políticos, denominados Trabalhadores Sem Terra. Conforme expõe Esmeraldo (2007),

o MST é um movimento social que defende e trabalha para a formação de sujeitos coletivos com uma identidade política e social de Trabalhadores Sem Terra. Ė um Movimento que instiga uma vontade e uma consciência voltada para uma ação política coletiva, pautada na matriz teórica leninista/marxista. 
Esta se move para construir e alicerçar a unidade entre os trabalhadores e para forjar a luta de classes (ESMERALDO, 2007, p. 265).

Entretanto, apesar desta particularidade, as mulheres, que no primeiro momento se reconhecem, assim como os homens, como sujeitos coletivos homogêneos, como Trabalhadoras Sem Terra,

ao longo de sua caminhada desenvolvem estratégias de luta, como: a participação em Comissões, a criação de um Coletivo de Gênero, a participação nos espaços de formação do Movimento, a reivindicação de inscrição do debate de gênero em todos os processos formativos, a inclusão de reivindicações de interesse da mulher nas pautas de negociação, a criação de uma política de cotas para a ocupação com equidade de homens e de mulheres nas instâncias de direção, para afirmarem uma identidade outra para si (ESMERALDO, 2007, p. 266).

Seguindo o pensamento da autora e o que a literatura aponta, considerando que historicamente, os movimentos sociais que adotam a hegemonia da divisão social de classe como central em suas lutas, não incorporam outras dimensões políticas como de gênero, de raça, de etnia, de geração, para não deslocarem o foco principal de suas ações. Portanto, o estudo indica que aos poucos a questão de gênero vai sendo incorporada nas discussões do Movimento.

Após estas considerações preliminares, cabe destacar que o estudo tem por objetivo identificar as relações de gênero no interior do Movimento dos Trabalhadores Sem Terra e se o processo educativo do MST tem contribuído para as ações e discussões sobre o tema.

Este trabalho faz parte de um projeto intitulado "Concepções teórico-práticas de educação e trabalho no MST" e contou com o financiamento do CNPQ. Neste estudo, a metodologia utiliza a abordagem qualitativa e as pesquisas bibliográfica, documental e a coleta de dados. A coleta de dados consistiu em entrevistas com coordenadoras de escolas localizadas em assentamentos do MST e, também, uma entrevista como uma ex-dirigente do Setor Nacional de Gênero do Movimento.

Para o desenvolvimento deste trabalho, realizaremos o seguinte percurso: iniciamos com uma breve reflexão sobre o conceito de gênero. Em seguida, abordamos a perspectiva de gênero na concepção pedagógica do MST e finalizamos com as ações desenvolvidas para as mulheres do Movimento desde o início até o estágio atual com o Coletivo Nacional de Gênero. Finalizamos apontando os avanços e os desafios a serem enfrentados. 


\section{O conceito de Gênero}

María Jesús Izquierdo (2006), utiliza o conceito de "gênero" como categoria analítica para compreender desigualdades sociais. Essa autora considera que a desigualdade fundamental entre homens e mulheres reside nas formas como os seres humanos se relacionam na produção da sua existência, ou seja,

a sociedade se acha estruturada em dois gêneros, o que produz e reproduz a vida humana, e o que produz e administra riquezas mediante a utilização da força vital dos seres humanos. Vemos que o setor produtivo da vida humana se organiza em condições de dependência com relação ao setor dedicado à produção da riqueza e à administração (IZQUIERDO, 2006, p. 48).

Conforme Medrado (2008), essa autora diferencia sexo e gênero, bem como desigualdades de gênero - distribuição desigual de poder em função do polo produção/reprodução da vida e produção/administração de riquezas - e desigualdades de sexo decorrentes do fato de essas atividades serem executadas por homens ou mulheres, desigualdades essas que podem, ou não, coincidir:

[...] em nossa sociedade o que se apresenta como específico do gênero feminino é o fato de que sua contribuição para a produção da existência é a produção da própria vida humana como tal em contraponto as atividades e posições sociais atribuídas aos homens de ter um trabalho assalariado e participar na vida política [...] (IZQUIERDO, 2006, p. 48).

Após estas breves conceituações de gênero, retomamos a seguir como o conceito vai ser abordado na Pedagogia do Movimento.

\section{A questão de gênero na Pedagogia do MST}

Caldart (2003), contribuí para o nosso entendimento sobre a Pedagogia do MST, ao afirmar que

O MST forma os Sem Terra colocando-os em movimento, o que quer dizer, em ação permanente; ações da dinâmica de uma luta social: ocupações, acampamentos, marchas, manifestações de solidariedade, construção de uma nova forma de vida nos assentamentos, conquista de escolas, atividades de formação... É pela ação que vão aprendendo que nada é impossível de mudar, nem mesmo as pessoas, seu jeito, sua postura, seu modo de vida, seus valores. As pessoas se educam nas ações porque é o movimento das ações que vai conformando o jeito de ser humano. As ações produzem e são produzidas através de relações sociais: ou seja, elas põem em movimento um outro elemento pedagógico fundamental que é o convívio entre as pessoas, a interação que se realiza entre elas, mediada pelas ferramentas herdadas de 
quem já produziu outras ações antes (cultura); nestas relações as pessoas se expõem como são, e ao mesmo tempo vão construindo e revisando suas identidades, seu jeito de ser (CALDART, 2003, p.54).

Especificamente sobre a formação para a questão do gênero, Araujo (2011), considera como um desafio, o desenvolvimento de um processo educativo que permita a superação da dominação machista imposta pela cultura que estamos inseridos, e um melhor entendimento sobre o tema.

Superar concepções tradicionais de família e de relacionamento entre gerações, também faz parte desta construção. Outro desafio é a superação do racismo e o aprofundamento da questão étnica. Outro ainda é o respeito às diferenças que existem no jeito de ser das pessoas, e uma preocupação especifica com os educandos portadores de necessidades especiais, para o que ainda não olhamos com atenção devida (ARAUJO, 2011, p.99-100).

O estudo desta autora citada, intitulado "A Pedagogia do Movimento Sem Terra e Relações de Gênero: incidências, contradições e perspectivas em Movimento", se utiliza da análise documental, para desvelar as questões do gênero no MST, problematizando como são percebidas e representadas, pela Pedagogia do MST, as diferenças entre os sexos, buscando analisá-las, não apenas no âmbito do cotidiano, mas em todas as esferas de vida dos Sem Terra.

Segundo Araujo (2011), a Pedagogia do MST em suas formulações trata das questões de gênero refletindo as relações e seu vínculo entre processos educativos mais amplos de organização da sociedade em suas relações e estruturas organizativas. Neste sentido, a autora afirma "que para o MST as relações sociais são conteúdos e a educação é mais que processo de ensino, é mais que escola. Ela corresponde a todas as práticas formais e não formais que vêm sendo construídas na luta do MST”(ARAUJO, 2011, p.90).

Conforme a autora citada, o próprio MST reconhece as desigualdades e a discriminação da mulher na sociedade e no campo tanto ao nível de sua inserção econômica quanto na esfera política. O que coloca a necessidade de pensar os processos de organização social e as intencionalidades pedagógicas.

Na concepção pedagógica do MST a educação deve ser integrada e articulada ao debate político e as problemáticas do campo onde se coloca a questão da opressão e exploração da mulher entre estas, as trabalhadoras rurais. Para Araujo (2011),

isso requer ter presente práticas sociais que propiciem novas relações nas dimensões tanto sociais, afetivas e cognitivas. Por outra parte, nesta concepção há uma compreensão da dimensão formadora fora da escola, no trabalho produtivo, nas lutas, assentamentos e acampamentos, nas diversas práticas sociais e na estrutura organizativa do Movimento (ARAUJO, 2011, p.93). 
Nesta direção, o MST tem buscado construir uma ação pedagógica e atuar como sujeito educativo para os (as) Sem Terra e, também, para o conjunto da sociedade de modo a contribuir de alguma maneira para reorientar as possibilidades de formação e vivências que induzam a práticas mais democráticas e solidárias nas relações de gênero.

Entretanto, ainda que identifiquemos todo um esforço do Movimento desde a década de 1980 neste sentido, destacamos a dificuldade de participação das mulheres em eventos e várias atividades do MST, pois as mães não tinham onde deixar as crianças. Foram criadas as cirandas infantis, e aos poucos, as mesmas, foram se constituindo como um tipo de escola itinerante em tempo integral. O Movimento passou a organizá-la durante suas atividades de mobilização para assegurar as condições da participação das mães sendo um espaço educativo destinado aos Sem Terrinha que junto com a família participam das atividades, eventos e mobilizações dos Sem Terra.

Portanto, as medidas concretas avançam à medida que os problemas são identificados e as propostas e tentativas para solução buscam ser viabilizadas. Do mesmo modo, que as cirandas, a demanda por educação infantil no MST, teve origem a partir das necessidades das mulheres, para que pudessem trabalhar nas cooperativas do Movimento. Destacamos a afirmação de Araujo (2011),

vimos que a demanda e a discussão da educação infantil surgiram a partir do trabalho nas cooperativas. Ou seja, não surge no debate das crianças, nem das mulheres, mas no debate econômico. A necessidade de integrar o trabalho das mulheres irá trazer a demanda das "creches" (ARAÚJO, 2011, p.121).

Diante das dificuldades, dos acertos e erros, das idas e vindas, o MST foi entendendo a necessidade de avançar para a organização das cirandas permanentes nas áreas de assentamento e acampamentos para uma maior participação das mulheres. O Setor de Educação abraçou a luta pela educação infantil, envolvendo outros aspectos como o tipo de educação necessária a formação da infância.

De acordo com Araujo (2011, p.122), “foi quando os papéis sociais na família e na organização do MST passam a ganhar visibilidade e provocar a busca de soluções", construindo uma preocupação coletiva com a necessidade de promover as condições para que as Mulheres Sem Terras possam ter o direito a escolarização, a participação política e seu reconhecimento enquanto trabalhadoras, dirigentes e militantes sociais. 


\section{A participação da mulher na luta do Movimento}

Segundo Mafort (2013), desde a criação do Movimento Sem Terra (MST) em 1984, existe a discussão sobre como envolver os diferentes sujeitos da luta no processo organizativo: homens, mulheres, jovens, idosos, crianças. Conforme a autora

Durante esse debate, a participação das mulheres se colocou como desafio para o MST. A organização de coletivos específicos de mulheres e a discussão sobre sua situação de opressão de classe e de gênero foi ao longo do tempo envolvendo o conjunto do Movimento, e foram na verdade as condições para o debate de gênero (MAFORT, 2013, p. 99).

É possível acompanhar a produção de uma preocupação em promover a participação das mulheres em todas as instâncias, setores e atividades do MST ao longo de sua história. Um trabalho, que mesmo com recuos e rupturas, permaneceu insistindo numa mudança acerca do lugar do feminino na luta. De acordo com Silva (2004), os assentamentos e acampamentos passaram a ter inclusive a incumbência de constituir grupo de mulheres que discutam questões específicas relacionadas à situação da "mulher no campo".

Silva (2004) enfatiza que é possível acompanhar em documentos e relatórios das reuniões acontecidas no início da década de 1980 que o MST vinha discutindo, um meio de organizar o trabalho com as mulheres do Movimento. A autora afirma que

nos Cadernos de Formação, a partir do $5^{\circ}$ número, passaram também a imprimir em suas páginas a preocupação em "inserir as mulheres na luta". Isso se observa nas figuras que ilustravam suas publicações oficiais, onde a representação do feminino começa a ser frequente, mesmo que no meio de 20 homens tenha apenas duas mulheres (SILVA, 2004, p.86).

Para Mafort (2013), foi no I Congresso Nacional do MST, realizado em 1985, que foram aprovadas dentre as normas gerais a organização de comissões de mulheres dentro do MST para discutir problemas específicos, particularmente,

o estímulo à participação das mulheres em todos os níveis de atuação, instancias de poder e representatividade, assim como combater toda a forma de discriminação das mulheres, a luta contra o machismo, e todas as manifestações que impedissem igualdade de direitos e condições das mulheres trabalhadoras (MAFORT, 2013, p.100-101).

Essa preocupação do MST em avançar nas discussões sobre a questão d a mulher, é corroborada por Silva (2004) ao apresentar as determinações presentes no capítulo VIII das "Normas Gerais" do MST publicadas em 1989. As Normas informam a preocupação de estabelecer e organizar regras gerais que disciplinem a construção do "novo" (novo sujeito 
social) numa perspectiva de mudanças em suas relações. De acordo com a autora, esse capítulo possui cinco artigos que versam sobre a "articulação das mulheres.” Dos quais destacamos:

51- O Movimento dos Trabalhadores Rurais Sem Terra deve estimular a participação das mulheres em todos os níveis de atuação, em todas as instâncias de poder, e de representatividade.

52- Devemos combater todo e qualquer tipo de discriminação às mulheres, em todas as atividades do Movimento, e lutar contra o machismo em todas as manifestações que impeçam a igualdade de direitos e condições das mulheres trabalhadoras.

53- Deve-se estimular a organização de comissões de mulheres dentro do Movimento dos sem-terra, nos assentamentos e nos acampamentos, para discussão dos seus problemas específicos. (MST, 1989 apud SILVA, 2004, p.87)

O trabalho de Silva (2004) vai descrevendo as publicações, os eventos que foram sendo realizados ao longo dos anos, discutindo as questões relacionadas "às companheiras" até chegar na constituição do Coletivo Nacional de Mulheres do MST, na segunda metade da década de 1990. Conforme a autora citada, a organização desse grupo oportunizou um maior número de materiais produzidos, além das discussões que buscavam fazer uma reflexão mais teórica sobre a questão das mulheres. Malfort (2013, p.100), considera que o debate sobre o desafio de construir novas relações de gênero e a necessária vinculação com o componente de classe contido no objetivo estratégico da Via Campesina e do MST levaram estas Organizações ao encontro com o legado feminista. Somente posteriormente a esse processo reflexivo procuraram incorporar em seu discurso a palavra gênero.

Corroborando a análise de Silva (2004), Mafort (2013), afirma que

por meio da organização destas comissões e coletivos de mulheres do/no MST, as lideranças femininas começaram a estudar e debater o conceito de gênero a partir de meados dos anos 1990. A necessidade de envolver o todos da organização neste debate deságua na criação do setor de Gênero no Encontro Nacional do MST em 2000. Este teria a tarefa de estimular o debate de gênero em instancias e espaços de formação da organização, de produzir materiais, propor atividades, ações e lutas que contribuíssem para a construção de condições objetivas para participação igualitária de homens e mulheres e assim fortalecendo o próprio MST (MAFORT, 2013, p.101).

Conforme Malfort (2013), a partir do Encontro Nacional do MST do Setor de Gênero, foram definidas as linhas das políticas de gênero a serem implantadas nos diversos espaços de atuação, dando ênfase tanto os aspectos da luta de gênero quanto da luta de classes e a transformação da sociedade. Destacamos as linhas políticas de gênero do MST (2005):

1. Garantir que o cadastro e o documento de concessão de uso da terra sejam em nome do homem e da mulher; 
2. Assegurar que os recursos e projetos da organização sejam discutidos por toda a família (homem, mulher e filhos que trabalham), e que os documentos sejam assinados e a execução e controle também sejam realizados pelo conjunto da família.

3. Incentivar a efetiva participação das mulheres no planejamento das linhas de produção na execução do trabalho produtivo, na administração das atividades e no controle dos resultados.

4. Em todas as atividades de formação e capacitação, assegurar que haja 50\% de participação de homens e mulheres;

5. Garantir que em todos os núcleos de acampamentos e assentamentos tenha um coordenador e uma coordenadora;

6. Garantir que em todas as atividades do MST tenha Ciranda Infantil;

7. Assegurar a realização de atividades sobre o tema gênero e classe em todos os setores e instâncias do MST;

8. Garantir a participação das mulheres na Frente de massa e no Sistema Cooperativista dos Assentados para incentivar as mulheres a ir para o acampamento, participar das atividades no processo de luta, e ser ativa nos assentamentos;

9. Realizar a discussão da cooperação de forma ampla, procurando estimular mecanismos que liberem a família de penosos trabalhos domésticos cotidianos, incentivando a organização de refeitórios, lavanderias comunitárias, etc;

10. Garantir que as mulheres sócias de cooperativas e associações com igualdade na remuneração das horas trabalhadas, na administração, planejamento e na discussão política e econômica;

11. Combater todas as formas de violência, particularmente contra mulheres e crianças que são as maiores vítimas da violência no capitalismo (MST, 2005, p.31).

Nas linhas políticas do gênero apresentadas, o MST propõe que se discuta a cooperação de forma ampla, procurando estimular mecanismos que liberem a família de penosos trabalhos domésticos cotidianos, incentivando a organização de refeitórios, lavanderias comunitárias, entre outras ações.

De acordo com Malfort (2013, p.101), com a definição destas linhas políticas, as mesmas, passaram a fazer parte da vida das famílias Sem Terra. "Ainda persistem muitos desafios na prática, mas a definição das linhas fortalece e estabelece metas que o conjunto do Movimento deve atingir”. Isso possibilita um novo significado à luta pela terra, em que todos e todas se sentem sujeitos participantes de um processo de mudança.

O MST vem propondo iniciativas que objetivam propiciar condições para a participação das mulheres. Estas iniciativas podem contribuir para repensar novas formas de relações nos diversos espaços; seja no lar, na escola, na roça, ou nas mobilizações. Conforme entrevista concedida pela ex-dirigente do setor de gênero e integrante da coordenação nacional do MST em 2014: 
no final da década de 1990, contávamos com uma ativa participação das mulheres na base do movimento, mas nos espaços de decisão política era muito masculinizado. O Movimento define as políticas de gênero, entre elas que em cada Núcleo de Base, tenha um homem e uma mulher. Mas na Direção Política do Movimento, isto só ocorreu a partir de 2006. Foi definida a composição de duas pessoas por Estado onde o MST está organizado, sendo um homem e uma mulher. Só a partir deste ano, conseguimos em nível nacional a participação das mulheres, pois a Direção nacional tinha em sua trajetória de direção que os melhores eram homens. Tivemos que trabalhar um processo de formação das mulheres, projeção de liderança, fala pública, para que as mulheres pudessem estar nesta posição. Este processo foi desenvolvido antes do ano de 2006 e então tivemos um coletivo de mulheres muito preparadas para esta posição na Direção Nacional do Movimento (MAFORT, 2014).

Conforme relato, é possível identificar ações voltadas à capacitação das mulheres em vários processos de formação (política, escolar, liderança, falar em público), proporcionados pelo Movimento. Apesar das dificuldades enfrentadas pelo MST para o desenvolvimento das questões de gênero no interior do movimento, no cotidiano de homens e mulheres "de carne e osso", cabe destacar também, o avanço obtido com a instituição da titulação conjunta da terra para lotes de assentamentos, instituído com a Portaria n. 981/2003 pelo Instituto Nacional de Colonização e Reforma Agrária. Essa garantia permitiu a mulher usufruir da renda e todos os benefícios sociais e econômicos e se colocar em condições de igualdade para gerir os créditos e projetos agrícolas (ARAUJO, 2011, p. 139).

\section{Considerações finais}

O MST vem incorporando as questões de Gênero em seus discursos e tem procurado dar seus passos, não importa se no interior de estratégias políticas ou econômicas. Mas, as antigas e sedimentadas estruturas de poder impõem, ainda, a necessidade do Movimento, repensar, e, sobretudo, transpor os limites em que as relações entre homens e mulheres estão colocadas.

$\mathrm{Na}$ trajetória histórica do desenvolvimento das questões de gênero no MST é possível identificar os avanços alcançados, como por exemplo, a titularidade conjunta, dando legalmente as mulheres os mesmos direitos de posse e uso da terra dentre outros aspectos abordados, como por exemplo, o fato das mulheres terem conseguido seus espaços na direção política do Movimento em nível nacional a partir de 2006, após um amplo processo de formação das mesmas. Entretanto, permanece o grande desafio de criar possibilidades de uma maior igualdade na divisão do trabalho realizado e de oportunidades para as mulheres Sem Terra. 
Portanto, a luta do Movimento deve persistir investindo no questionamento das velhas estruturas hierárquicas e verticais de poder, as quais têm fortalecido a representação masculina nas instâncias associativas e nas direções, mantendo as mulheres em condições numéricas bem inferiores aos homens, diminuindo sua força de pressão, bem como dificultando a sua formação técnica em função da falta de oportunidades para essa qualificação, o que diminui ainda mais as suas possibilidades de inserção nestes espaços, indicando que essa discussão ainda tem um longo caminho pela frente, pois sabemos que a cultura instituída em nossa sociedade não muda facilmente.

\section{REFERÊNCIAS}

ARAÚJO, Djacira Maria de Oliveira. A Pedagogia do Movimento Sem Terra e as Relações de Gênero: incidências, contradições e perspectivas em movimento. 154p. 2011. Dissertação. (Mestrado em Ciências Sociais). Faculdade de Educação da Universidade Federal da Bahia, Salvador, 2011.

CALDART, Roseli Salete. Movimento Sem Terra: lições da Pedagogia. Revista Currículo Sem Fronteiras. Porto Alegre, v.3.n.1.p.50-59, jan./jun. 2003

ESMERALDO, Gema Galgani S. L. Re-significações do Feminismo e da Política em Práticas de Mulheres Assentadas. In: VALE, Alexandre Fleming C. \& PAIVA, Antonio Cristian S. (Orgs.). Estilísticas da Sexualidade. Fortaleza: Programa de Pós-Graduação em Sociologia/UFC; Campinas: Pontes Editores, p. 95-113, 2007.

IZQUIERDO, María Jesús. "Los costos ocultos de la masculinidad". La Manzana. Revista Internacional de Estudios sobre Masculinidades, Puebla, México: Benemérita Universidad Autónoma de Puebla, v. I, n. 2, 2006. Disponível em: www.estudiosmasculinidades.buap.mx Acesso em: 16 mar. 2008.

MAFORT, Kelli Cristine de Oliveira. A hegemonia do agronegócio e o sentido da reforma agrária para as mulheres da Via Campesina. 134p. 2013. Dissertação. (Mestrado em Ciências Sociais). Faculdade de Ciências e Letras de Araraquara da Universidade Estadual Paulista, Araraquara, 2013.

MAFORT, Kelli Cristine de Oliveira. Mulheres do MST criam novas relações de gênero dentro e fora do movimento. Página do MST. Disponível em: http://www.mst.org.br/node/15654 Acesso em 20 de mar. de 2014.

MEDRADO, Benedito; LYRA, Jorge. Por uma matriz feminista de gênero para os estudos sobre homens e masculinidades. Revista Estudos Feministas. Florianópolis, v.16, n.3, set./dez. 2008. Disponível em: http://dx.doi.org/10.1590/S0104-026X2008000300005 Acesso em 28 de jun. de 2015.

MOVIMENTO DOS TRABALHADORES SEM TERRA - MST. Construindo Novas Relações de Gênero - desafiando relações de poder. Brasília: Ministério do Trabalho e do Emprego, 110p, 2005. 
SILVA, Cristiani Bereta. Homens e Mulheres em Movimento. Relações de Gênero e Subjetividades no MST. Florianópolis: Momento Atual, 2004.

\section{Entrevistas:}

MAFORT, Kelli Cristine de Oliveira. Kelli Cristine de Oliveira Mafort: depoimento [Nov.2014]. Entrevistadoras: Claudia de Pádua Sabia e Tânia Suely Antonelli Marcelino Brabo. FFC/UNESP, Campus de Marília: 4 arquivo mp3(2:00). Entrevista concedida ao Projeto Concepções teórico-práticas de educação e trabalho no Movimento dos Trabalhadores Rurais Sem Terra (MST).

\section{Como citar este artigo}

SABIA, Claudia Pereira de Pádua; BRABO, Tânia Sueli Antonelli Marcelino. Relações de gênero no Movimento dos Trabalhadores Sem Terra - MST: perspectivas a partir da concepção pedagógica do movimento. Revista Ibero-Americana de Estudos em Educação, Araraquara, v $14, \quad$ n. esp. 2, p. 1601-1612, jul., 2019. E-ISSN: 1982-5587. DOI: 10.21723/riaee.v14iesp.2.12648

Submetido em: 26/10/2019

Revisões requeridas: 25/03/2019

Aceite em: 30/04/2019

Publicado em: 26/06/2019 